\title{
AN EFFECTIVE UTILIZATION OF SOLAR ENERGY FOR SUSTAINABLE DEVELOPMENT - A FUTURE TECHNOLOGICAL DEVELOPMENT IN INDIA
}

\author{
AASHISH. C. I
}

Assistant Professor, Department of Management and Commerce, Amrita University, Mysuru Campus, Karnataka, India

Solar energy being the renewable resource of energy has not been tapped for its maximum utilization. Even though, this energy is used extensively for street lighting, home light, and other appliances, it has not been used for the automobiles from the past. This has been because of the abundant availability of crude oil until recently. Since crude oil is exhaustible energy, this energy is exploited to such an extent that, now it is becoming inevitable to look at other sources of energy, since it is on the verge of exhaustion. At the same time, scientists have come out with a new theory that, one of the reasons for global warming is the extraction of crude oil and black gold, which otherwise is called as coal. In fact, it is considered that there is no proper heat absorption of the sunlight and it is becoming less and less day by day, as the extraction of the crude is increasing and also the extraction of the crude oil would become more costly than the cost of extraction, by another decade there by ending the extraction of crude oil.

KEYWORDS: Renewable Resource, Economies of Scale, Sustainable Development \& Exhaustible Energy
\end{abstract}

Received: Sep 15, 2017; Accepted: Oct 07, 2017; Published: Oct 17, 2017; Paper Id.: IJMPERDOCT201741

\section{OBJECTIVES}

- To study the potential utilization of solar energy and awareness amongst the age groups, as a sustainable development.

- To analyze the success of technology utilization and its impact with respect to the traditional technology

- To evaluate the comparison between conventional energy and solar energy

- To find the effect of protecting the extraction of non-renewable resource

\section{INTRODUCTION}

The next source of energy would most likely be the solar energy. In the recent analysis experts feel that, avoiding crude oil extraction would be saving more than its cost that is involved in extraction. By doing so, they not only save but also reduce the emission of carbon-Mon-oxide which is hazardous to the environment. Also at the same time the number of vehicle buying and owing is also growing substantially and according to statistics it is said that by 2020 there would be two cars and four two wheelers in every house on an average in India, it means that as the number of vehicles are increasing, there would be an increase in the price of fuel. This may suffice for the current requirement, but in the future, it will be sure that there might not be space for movement of these kinds of designing vehicles and also the non-renewable energy. It is equally important that people should be made aware about this unsustainable development of the crude oil and the sustainable development of the solar energy for the future. As all new technologies come with an advantage, there are many disadvantages to it also. As of now many 
companies are still concentrating on the technological up gradation of their vehicles to ensure it meets the expectations of the customers. In the bargain, of what it used to be just the manufacturing of the cars giving mileage as the secondary priority for long years, now that they have started to concentrate more on the mileage because of an increase in the cost of the fuel. (Andrés Arias-Rosales and Ricardo Mejía-Gutiérrez- Low -15 June 2016) [1]. Many cars that were giving mileage as less as eight to nine kilometers per liter have started concentrating on the vehicles that have started to give anything above twenty kilometers per liter of fuel. Mahindra's are the first of the companies to have come out with the concept of sun-to-car, meaning that the sunlight is directly being utilized for running vehicle through the concept of photovoltaic cells. In consent with the National Mission on electric mobility, Indian Government has already deployed solar and electric concept, which is presently being called as hybrid concept. The projection is about Rs.5-7 million by the end of 2020. This shows that a step forward has already been taken to ensure the smooth functioning of the organization in short and the Indian economy at large. According to statistics, India could save approximately about 4.8 billion barrels of oil and about 280 million tons of carbon-Mon-oxide emission can be avoided by the method of adopting hybrid cars. But it requires a monitoring system for a proper recharging and also the maintenance of it. (Enrique Guerrero Merino and Manuel A. Duarte-Mermoud -23 September 2015) [2]. this means that, it is a huge saving for the ex-Chequer and simultaneously a huge advantage of the economies of scale. Effectively as a first five year plan, many companies have started adopting the "5 C's framework, meaning clean, convenient, clear, cost effective, and clever. One of the reasons being the increase in the ownership of cars in the next five years is projected by many automobile companies at the rate of 16 percent growth every quarter. This means that for whatever reasons, it could be to own a vehicle or as a necessary purpose, that consumers are buying automobiles. One of the statistics says that on an average Indians normally travel about a $100 \mathrm{~km}$ each day. This data is very useful information for the automobile companies come out with the technology that can suit the Indian economic factors. One of the major economic factors that is worrying India is the rate of economy. Therefore a date like $100 \mathrm{~km}$ can help the companies to come out with cost effective technology that would help the companies to grow incrementally, in turn, help the companies to go through gestation time, as many start-up companies would do that. Initially they start with capturing smaller segment and then once it gets established, they would go for premium vehicles and larger economies of scale. But Indian market being very volatile and turbulent, has to be surveyed thoroughly to understand the acceptance of these technologies. But as easy as said and done, this may take little time before the investors get convinced for the project. Research and development is being conducted in the United Kingdom and U.S.A, to bring the carbon level to zero, by 2050. (Samantha A. Janko, Michael R. Arnold, Nathan G. Johnson -11 July 2016) [3]. Presently, India is looking for the utilization of electric resource. Recently, when the Prime Minister of India had visited the USA, invited Tesla Motors to invest in India, which is an electric car. Initially, even though these cars run on chargeable batteries, they may slowly be converted to solar with the extensive utilization of research and development. Feasibility is the technology of distributed hydrogen production from renewable energy sources and the financial contribution from UK motorists on environmental grounds. (Geoffrey D. Southall AnshumanKhare -19-5-2016) [4]. At the outset it looks like electric and solar technology seems to be different, rest assured that these can be combined for economy development. World across, there have been experiments being conducted to bring electric automotive, which is the present environmental development. (David B Price et. al)[5] - opined that Outdoor air pollution has long been known for its adverse effects on human health, being responsible for the deaths of more than 3 million people worldwide every year. If at all, every country succeeds in the technology, again, there would be a shortage of electric power. The only alternative left would be to use solar energy, which is inexhaustible. Presently there has been an experiment being conducted to find the comparative 
analysis between the utilization of traditional resources like the crude oil, for which there has already been in the capital investment allocated for its optimum utilization. Many automobile companies which have invested in its conventional manufacturing should be able to break even and the profit so earned out of it, which would be substantial, can only be invested in the future technology. This experiment of comparison is being conducted by Porsche, and that is in comparison with the traditional energy, a step forward in being proactive towards a prospective future. (Friedbert Pautzke. Et. al)[6]. The prospective future is predicted by many companies, as guessed it right, is the solar energy. Some of the objectives of this study are mentioned below.

Table

\begin{tabular}{|c|c|c|c|c|c|c|}
\hline Age & Awareness & $\begin{array}{c}\mathbf{X}- \\
\mathbf{X}=\mathbf{x}\end{array}$ & \begin{tabular}{c}
$\mathbf{Y}=\mathbf{y}$ \\
\hline 25
\end{tabular} & $2 \mathbf{2 X}$ & $\mathbf{2 y}$ & $\mathbf{x y}$ \\
\hline 30 & 5 & -12.5 & -6.3 & 156.25 & 39.69 & 78.75 \\
\hline 35 & 5 & -7.5 & -3.3 & 56.25 & 10.89 & 24.75 \\
\hline 40 & 8 & 2.5 & -0.7 & 6.25 & 0.49 & -1.75 \\
\hline 45 & 10 & 7.5 & 3.7 & 56.25 & 7.29 & 27.75 \\
\hline 50 & 20 & 13.5 & 11.7 & 156.26 & 136.89 & 157.97 \\
\hline$\sum 225$ & $\sum 50$ & & & $\sum 438$ & $\sum 206.14$ & $\sum 295.7$ \\
\hline
\end{tabular}

A survey conducted showed the correlation between age and awareness, which is important as one of the objectives.

$$
\begin{aligned}
& r=\left(\frac{\sum X Y}{\sqrt{\sum x^{2} \sum \cdot y^{2}}}\right) \\
& r=295.7 / \sqrt{ }(438)(206.14) \\
& r=0.9840
\end{aligned}
$$

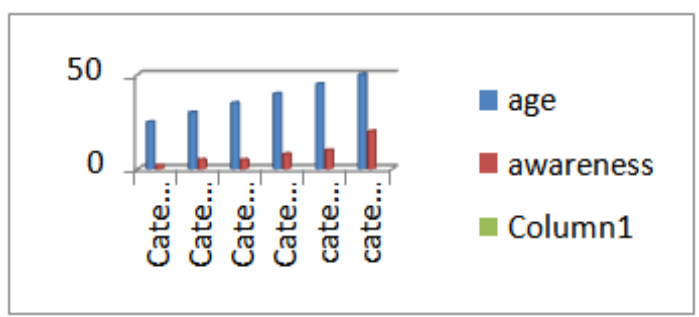

Figure

Therefore, there is a strong correlation between age factor and awareness amongst people.

\section{Analysis and Interpretation}

It is significantly seen that in the age group of 25 years are not aware of the consequence of the exhaustible energy Nordhaus, W. D. (1979) efficient use of energy resources. [7]. The awareness in this age group is only about 4\%, whereas, in the age group of 30 and 35 there is awareness of 10\%. Some of the factors that have made this age group aware are their educational background. In the age group of $45 \mathrm{yrs}, 20 \%$ of the people are awareness because they have been paying for the fuel and the price of the fuel has increased since their realization. But it is strongly seen that in the age group of 50, they have not only realized, but are also aware to an extent of $40 \%$ that the sectors are going towards unsustainable development, Wall, G. (1997). Sustainable tourism-unsustainable [8]. This age group is of the opinion that, the 
automobile sectors Harwit, E. (1996). Japanese investment in China: Strategies in the electronics and automobile sectors. Asian Survey [9] should conduct certain research and development, and still be able to retain the traditional energy, as such. One of the options that came to them was, the solar energy, even though the awareness should be better. But, for the limitations of this study, I am sure, a research conducted in a higher age group, would give us a trend analysis Hirsch, R. M., Slack, J. R., \& Smith, R. A. (1982). Techniques of trend analysis for monthly water [10] that more the age group better would be the awareness.

\section{CONCLUSIONS}

The running of automobiles is inevitable, but it mainly depends on the kind of energy that would be utilized for the movements. An initiation towards or a step forward towards sustainable development has to be taken both by the Government and also by the research and development department of the individual automobile companies. Since it is known that the conventional energy would exhaust soon, solar energy is the next option. At the same time, environmental researchers are of the view that protecting the non-renewable resources is essential for sustainable development. Even though, there is a consortium of the automobile companies, when it comes to their trade secrets, no company would like to reveal their confidential matters to the other because of competition. What should the Government and the companies keep in mind, so far as the Indian market is concerned, is about the cost of manufacturing because India is one such place which is very much price sensitive. At the same time the phase-off the fuel vehicles cannot happen all of a sudden, it should be done in stages, ensuring incremental changes in the shift of fuel to solar. Since this looks a permanent solution, it required a good capital investment that helps the industry in particular and the economy at large. The climatic and weather conditions are also conducive and presently of what India has tapped the market is only $2 \%$ of it. Therefore, India has a huge potential for capitalising the solar energy.

\section{REFERENCES}

1. Andrés Arias-Rosales and Ricardo Mejía - Gutiérrez- Low (15 June 2016)- stated that Concentration Photovoltaics (LCPV) and tracking methods can be integrated in V-Trough solar devices to increase their effective solar harvesting area through low-cost non-imaging optics.

2. Enrique Guerrero Merino and Manuel A. Duarte-Mermoud (23 September 2015)- The author is of the opinion that "complete monitoring system is in charge of estimating important variables such as the battery state of charge (SoC) and all circulating currents and voltages on the electric circuit, as well as temperatures and other important data concerning the different car devices.

3. Samantha A. Janko, Michael R. Arnold, Nathan G. Johnson (11 July 2016) - stated that amount of research in photovoltaic cells and practical implementation will reduce carbon emissions by 2050 in USA would come to zero if all the vehicles would run with solar technology.

4. Geoffrey D. SouthallAnshumanKhare (19-5-2016)- pointed out that feasibility of distributed hydrogen production from renewable energy sources and the financial contribution from UK motorists on environmental grounds.

5. David B Price et. al., Ian D Pavord, Mike Thomas, Christopher J Corrigan, Andrew M Wilson, Elizabeth V Hillyer, MarjanKerkhof (2013)- opined that Outdoor air pollution has long been known for its adverse effects on human health, being responsible for the deaths of more than 3 million people worldwide every year. 
6. FriedbertPautzke, FabianRaschke, Matthias Drossel, Matthias Wiemers, Robert Siebrech- He compares this vehicle with a well-known commercial car, the Porsche Panamera equipped with an 80 liter tank for its mileage.

7. Nordhaus, W. D. (1979). Efficient use of energy resources.

8. Wall, G. (1997). Sustainable tourism-unsustainable development. Tourism, development and growth: The challenge of sustainability, 33-49.

9. Harwit, E. (1996). Japanese investment in China: Strategies in the electronics and automobile sectors. Asian Survey, 36(10), 978-994.

10. Hirsch, R. M., Slack, J. R., \& Smith, R. A. (1982). Techniques of trend analysis for monthly water quality data. Water resources research, 18(1), 107-121. 
